\title{
Combustion synthesis of Hf-doped zirconolite-rich composite waste forms and the aqueous durability
}

\author{
Kuibao ZHANG ${ }^{a, b,}{ }^{*}$, Dan $\mathrm{YIN}^{a}$, Zongsheng $\mathrm{HE}^{a}$, Baozhu $\mathrm{LUO}^{a}$, Haibin $\mathrm{ZHANG}^{c}$ \\ ${ }^{a}$ State Key Laboratory of Environment-friendly Energy Materials, Southwest University \\ of Science and Technology, Mianyang 621010, China \\ ${ }^{b}$ National Defense Key Discipline Lab of Nuclear Waste and Environmental Safety, \\ Southwest University of Science and Technology, Mianyang 621010, China \\ ${ }^{c}$ Institute of Nuclear Physics and Chemistry, China Academy of Engineering Physics, Mianyang 621900, China
}

Received: January 22, 2019; Revised: April 23, 2019; Accepted: May 3, 2019

(C) The Author(s) 2019.

\begin{abstract}
Zirconolite is recognized as one of the most durable waste matrices for the disposal of high-level radioactive wastes (HLWs). In this study, $\mathrm{HfO}_{2}$ was employed as the surrogate of tetravalent actinides. Hf-bearing zirconolite-based composite waste forms $\left(\mathrm{CaZr}_{1-x} \mathrm{Hf}_{x} \mathrm{Ti}_{2} \mathrm{O}_{7}\right)$ were rapidly prepared by combustion synthesis (CS) using $\mathrm{CuO}$ as the oxidant, where quick pressing (QP) was introduced to obtain densified samples. Similar as solid state reaction process, the $\mathrm{Zr}$ site of zirconolite can be totally occupied by $\mathrm{Hf}(x=1.0)$ under the CS reaction. The original $2 \mathrm{M}$ zirconolite structure was maintained and a small amount of perovskite impurity phase was generated in the final products. The aqueous durability of representative sample (Cu-Hf-0.6) was tested, where the 42-day normalized leaching rates $\left(L R_{i}\right)$ of $\mathrm{Ca}, \mathrm{Cu}$, and $\mathrm{Hf}$ are $0.25,3.10 \times 10^{-2}$, and $1.11 \times 10^{-8} \mathrm{~g} \cdot \mathrm{m}^{-2} \cdot \mathrm{d}^{-1}$.
\end{abstract}

Keywords: combustion synthesis (CS); nuclear waste; $\mathrm{HfO}_{2}$; zirconolite; aqueous durability

\section{Introduction}

The disposal of high-level radioactive wastes (HLWs) has long been a great and urgent challenge for the nuclear industry $[1,2]$. Due to the long term radiotoxicity of minor actinides (MA, such as $\mathrm{Np}, \mathrm{Am}, \mathrm{Cm}$, etc.) recovered from spent fuel reprocessing, the separation of these actinides and their final disposal in durable matrices are of prime importance. Advanced materials can enable enhanced performances of nuclear waste forms with promoted safety margins and chemical flexibility [3]. Vitrification using borosilicate or phosphate

\footnotetext{
* Corresponding author.

E-mail: xiaobao320@163.com
}

glasses is generally recognized as the first generation waste management method. In recent decades, highly durable ceramic materials have been proposed as an alternative medium for HLW immobilization [4-6]. The naturally existed zirconolite and pyrochlore are important actinide-bearing ceramic materials, which exhibit excellent chemical and physical durability over geological time scales [7-12]. Zirconolite (ideally $\mathrm{CaZrTi}_{2} \mathrm{O}_{7}$ ) was also developed as a crystalline phase to sequester $\mathrm{Pu}$ from surplus nuclear weapons, which makes it receive great attention as a potential waste form [13].

Zirconolite is formed by the stacking layers of edge shared Ti-O polyhedra $\left(\mathrm{TiO}_{5}\right.$ and $\left.\mathrm{TiO}_{6}\right)$ and layers of $\mathrm{Ca}^{2+}$ and $\mathrm{Zr}^{4+}$ cations [14]. Due to that the $\mathrm{Ti}^{4+}$ and $\mathrm{Zr}^{4+}$ ions can be mutually occupied, the zirconolite 
structure can sustain a wide range of stoichiometry as $\mathrm{CaZr}_{x} \mathrm{Ti}_{3-x} \mathrm{O}_{7}$ with $x=0.80-1.37$ [15]. In addition, zirconolite can transform to different polytypes with close structure arrangements, such as 3T (trigonal), $3 \mathrm{O}$ (orthorhombic), 2M, and 4M (monoclinic) [16]. The differently coordinated polyhedra enable zirconolite to accommodate large cations into its crystal structure as solid solutions. Naturally existed zirconolite demostrates many different combinations of element substitutions, excellent chemical flexibility, as well as excellent resistance to radiation damage and aqueous dissolution [17]. And zirconolite-based ceramic material has been recognized as one of the most promising matrice phase for nuclear waste disposal $[18,19]$.

In the past, zirconolite-based waste forms were mainly synthesized using traditional methods, such as liquid phase synthesis (hydroxide and sol-gel methods) and solid state reaction sintering [20-22]. These approaches are usually time consuming and costly. High temperature $\left(1400{ }^{\circ} \mathrm{C}\right.$ or higher) sintering is an indispensable procedure to obtain crystal lattice disposal of actinide-bearing wastes, which inevitably induce the evaporation of volatile nuclides (such as highly radioactive $\mathrm{U}, \mathrm{Tc}, \mathrm{Sr}$, and $\mathrm{Cs}$ elements). Meanwhile, compulsive densification process (such as hot pressing or hot-isostatic pressing) should be conducted to get highly compact samples, which cause the synthesis process more complicated [22]. Recently, reactive spark plasma sintering has been conducted to rapidly synthesize single-phase zirconolite under low temperature $\left(1200{ }^{\circ} \mathrm{C}\right)$ [23]. Besides that, Muthuraman and his coworkers [24] have proposed combustion synthesis (CS, similar as self-propagating high temperature synthesis, SHS) route for the management of nuclear wastes. Because of the special advantages of high speed, low energy consumption, and simple equipment, the CS technique has been considered as a candidate method for environment protection, such as stabilization of radioactive and toxic wastes [25-27]. It is worth pointing out that the reaction speed and generated temperature of CS can be tailored by adjusting the ingredients of raw reactants. For nuclear waste immobilization, CS route is advantageous for some special applications when the implement environment is confined. Thus, it is valuable to explore the feasibility of zirconolite-based waste forms using the CS process.

In our previous studies, we have investigated the CS preparation of $\mathrm{Ce}$ and $\mathrm{Nd}$ doped zirconolite-rich waste forms using $\mathrm{Ca}\left(\mathrm{NO}_{3}\right)_{2}, \mathrm{CuO}, \mathrm{MoO}_{3}$ as the oxidants and $\mathrm{Ti}$ as the reductant [27-30]. $\mathrm{CeO}_{2}$ has been widely employed as the surrogate of tetravalent actinides (such as $\mathrm{Pu}$ and $\mathrm{U}$ ). However, the incorporated $\mathrm{Ce}^{4+}$ is usually reduced to $\mathrm{Ce}^{3+}$ under high temperature sintering, as well as the reductive atmosphere of CS process, which leads to that Ce preferentially occupies the Ca site rather than the $\mathrm{Zr}$ site of zirconolite [30-32]. From the viewpoint of charge state, Ce is not an ideal surrogate of tetravalent actinides. Actually, $\mathrm{Hf}$ is a better simulate element of tetravalent actinides (especially $\mathrm{Pu}$ ) over $\mathrm{Ce}$ as the charge state of $\mathrm{Hf}^{4+}$ is very stable. And $\mathrm{Hf}$ exhibits identical density and solubility as $\mathrm{Pu}$ in the vitrious waste forms $[33,34]$. On the other hand, Hf is considered as a neutron poison for fission reactions because $\mathrm{Hf}$ exhibits much higher thermal neutron capture cross-section than $\mathrm{Zr}$ (104 barns for $\mathrm{Hf}$ and 0.184 barns for $\mathrm{Zr}$ ) [35]. Thus, zirconolite-rich ceramics and glass-ceramics with $\mathrm{Zr}$ partially or totally substituted by Hf can prevent critical event for the nuclear waste forms heavily loaded with fissile actinide isotopes of ${ }^{239} \mathrm{Pu}$ and ${ }^{235} \mathrm{U}$ [36].

In this study, $\mathrm{HfO}_{2}$ was employed as the surrogate of tetravalent actinides. As $\mathrm{Zr}^{4+}$ and $\mathrm{Hf}^{4+}$ cations demonstrate nearly identical ionic radius $(0.78$ and $0.76 \AA$ for $\mathrm{Zr}^{4+}$ and $\mathrm{Hf}^{4+}$, respectively) and belong to the same column in periodic table, these two elements show very close chemical properties and are expected to be incorporated with similar crystal structure [37]. According to charge balance and ionic radius, $\mathrm{Hf}^{4+}$ was designed to substitute the $\mathrm{Zr}$ site of zirconolite. In order to prepare dense samples, quick pressing (QP) was introduced after the completion of $\mathrm{CS}$ reaction. The $\mathrm{HfO}_{2}$-doped zirconolite-rich waste forms were prepared by the CS/QP process using $\mathrm{CuO}$ as the oxidant and $\mathrm{Ti}$ as the reductant. The loading capacity of $\mathrm{HfO}_{2}$ (the $x$ value of $\mathrm{CaZr}_{1-x} \mathrm{Hf}_{x} \mathrm{Ti}_{2} \mathrm{O}_{7}$ ) was explored. In addition, the phase composition, site occupancy, densification, and microstructure were investigated. The aqueous durability of representatively solidified Hf-doped sample (Cu-Hf-0.6) was also evaluated using standard Materials Characterization Center (MCC-1) leaching test [38].

\section{Experimental details}

A series compositions of Hf-doped zirconolite-rich waste forms with the chemical stoichiometry of 
$\mathrm{CaZr}_{1-x} \mathrm{Hf}_{x} \mathrm{Ti}_{2} \mathrm{O}_{7}(x=0.2,0.4,0.6,0.8,1.0$, named as $\mathrm{Cu}-\mathrm{Hf}-0.2$ to $\mathrm{Cu}-\mathrm{Hf}-1.0$, respectively) were synthesized by $\mathrm{CS}$ route. Analytical grade (AR) $\mathrm{CuO}, \mathrm{CaO}, \mathrm{Ti}$, $\mathrm{TiO}_{2}, \mathrm{ZrO}_{2}$, and high purity $\mathrm{HfO}_{2}(\geqslant 99.0 \mathrm{wt} \%)$ were purchased as the raw materials. The designed CS reactions are demonstrated as follows:

$$
\begin{aligned}
& 2 \mathrm{CuO}+\mathrm{CaO}+\mathrm{Ti}+\mathrm{TiO}_{2}+(1-x) \mathrm{ZrO}_{2} \\
& +x \mathrm{HfO}_{2} \rightarrow \mathrm{CaZr}_{1-x} \mathrm{Hf}_{x} \mathrm{Ti}_{2} \mathrm{O}_{7}+2 \mathrm{Cu}
\end{aligned}
$$

The weight percentages of raw reactants are listed in Table 1, where the yields of Hf-zirconolite are also included. About $20 \mathrm{~g}$ raw materials were weighed and sufficiently mixed using agate mortar. The homogenized raw powders were pressed into cylindrical pellets with diameter of $25 \mathrm{~mm}$ and height of about $12 \mathrm{~mm}$. The preformed samples were subsequently subjected to $\mathrm{CS} / \mathrm{QP}$ preparation as illustrated in Fig. 1. The combustion reaction was triggered by a heated tungsten wire, which was motivated by a direct voltage of $30 \mathrm{~V}$ and current of $50 \mathrm{~A}$. Silica sand was filled into the stainless steel mould as heat insulator and pressure transmission medium. Before pressure exertion, the combustion temperatures of the samples' center part were measured by a W/Re 5/26 thermocouple, which was connected with an XME2002/U paperless recorder to directly monitor the temperature curve.

The as-synthesized specimens were pulverized into fine powders, which were characterized by X-ray diffractometer (XRD; Rigaku Corporation, Tokyo, Japan) with $\mathrm{Cu} \mathrm{K} \alpha$ radiation to obtain the phase compositions. The XRD result of typical Cu-Hf- 0.6 sample was subjected to Rietveld refinement using Fullprof-2k software package. After the combustion was finished for 20-30 s, the red-hot samples were pressed by a hydraulic pressure of $45 \mathrm{MPa}$ with $60 \mathrm{~s}$ holding time. The finally obtained products with high relative density were sliced and polished on abrasive finishing machine using $0.5 \mu \mathrm{m}$ diamond pastes. After cleaning and drying, the samples were observed using field-emission scanning electron microscope (FESEM;
Zeiss Ultra-55, Oberkochen, Germany). The phase composition and elemental distribution of solidified $\mathrm{Cu}$-Hf-0.6 sample were analyzed from the results of energy-dispersive X-ray spectrometer (EDX) attached with the FESEM equipment. The chemical durability was evaluated according to the standard MCC-1 leaching test, where the $\mathrm{Cu}-\mathrm{Hf}-0.6$ sample was immersed in $90{ }^{\circ} \mathrm{C}$ deionized water for $1,3,7,14,21$, $28,35,42$ days, and the leachates were retrieved after each interval. The selected Cu-Hf-0.6 sample was cut and grinded to external dimension of $8.50 \mathrm{~mm} \times 4.78 \mathrm{~mm}$ $\times 4.84 \mathrm{~mm}$. Thus, the specimen surface area to leachate volume ratio $\left(S_{\mathrm{A}} / V\right.$ value $)$ is $2.62 \mathrm{~m}^{-1}$, which conforms to the requirement of ASTM leaching standard $\left(S_{\mathrm{A}} / V=\right.$ $\left.0.5-10.0 \mathrm{~m}^{-1}\right)$. Fresh deionized water $(80 \mathrm{~mL}$ every time) was added to replace the leachate after each interval. The concentrations of $\mathrm{Ca}$ and $\mathrm{Cu}$ in the leachates were obtained by inductively coupled plasma (ICP) analysis using an iCPA 6500 spectrometer, while Hf was tested by inductively coupled plasma-mass spectrometry (ICP-MS) analysis using an Agilent $7700 \times$ spectrometer.

\section{Results and discussion}

\section{1 Combustion temperature and XRD analysis of Hf-doped samples}

The combustion experiments of the above-mentioned Hf-doped samples were successfully conducted. The results demonstrate that all the designed green bodies could be ignited by tungsten wire with self-propagation reaction. The combustion reaction lasted for about $10 \mathrm{~s}$ after ignition, which means the reaction speed is about 2-3 $\mathrm{mm} / \mathrm{s}$. The center temperatures of all these reactions were collected by thermocouple as depicted in Fig. 2. The peak temperatures of these five samples (Cu-Hf-0.2 to Cu-Hf-1.0) are measured to be 1481,

\begin{tabular}{|c|c|c|c|c|c|c|c|c|}
\hline \multirow{2}{*}{ Sample number } & \multicolumn{6}{|c|}{ Weight percentage of the raw materials ( $w t \%)$} & \multirow{2}{*}{ Yield of Hf-zirconolite (wt\%) } & \multirow{2}{*}{ Total $(w t \%)$} \\
\hline & $\mathrm{CuO}$ & $\mathrm{CaO}$ & $\mathrm{Ti}$ & $\mathrm{TiO}_{2}$ & $\mathrm{ZrO}_{2}$ & $\mathrm{HfO}_{2}$ & & \\
\hline $\mathrm{Cu}-\mathrm{Hf}-0.2$ & 43.62 & 10.24 & 100 & 7.30 & 18.02 & 7.69 & 65.16 & 100 \\
\hline $\mathrm{Cu}-\mathrm{Hf}-0.4$ & 42.28 & 9.92 & 100 & 7.08 & 13.10 & 14.91 & 66.23 & 100 \\
\hline $\mathrm{Cu}-\mathrm{Hf}-0.6$ & 41.01 & 9.62 & 100 & 6.86 & 8.47 & 21.70 & 67.24 & 100 \\
\hline $\mathrm{Cu}-\mathrm{Hf}-0.8$ & 39.81 & 9.34 & 100 & 6.67 & 4.11 & 28.09 & 68.20 & 100 \\
\hline $\mathrm{Cu}-\mathrm{Hf}-1.0$ & 38.68 & 9.08 & 100 & 6.48 & 0 & 34.12 & 69.10 & 100 \\
\hline
\end{tabular}

Table 1 Weight percentage of raw reactants for the Hf-doped samples 


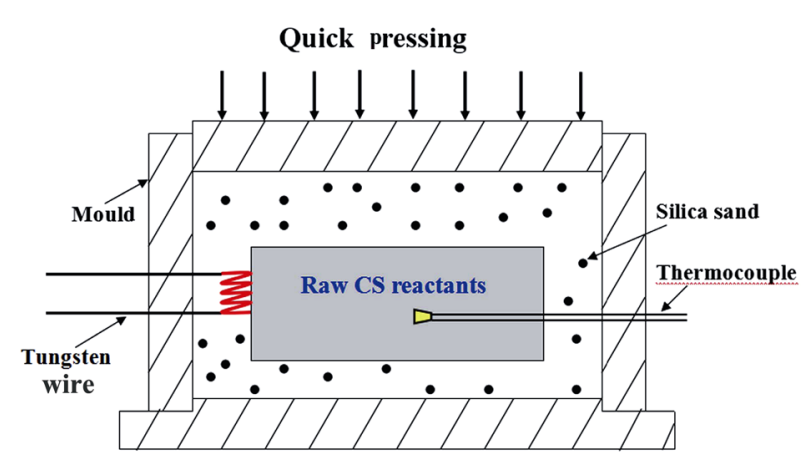

Fig. 1 Schematic diagram of the CS/QP method.

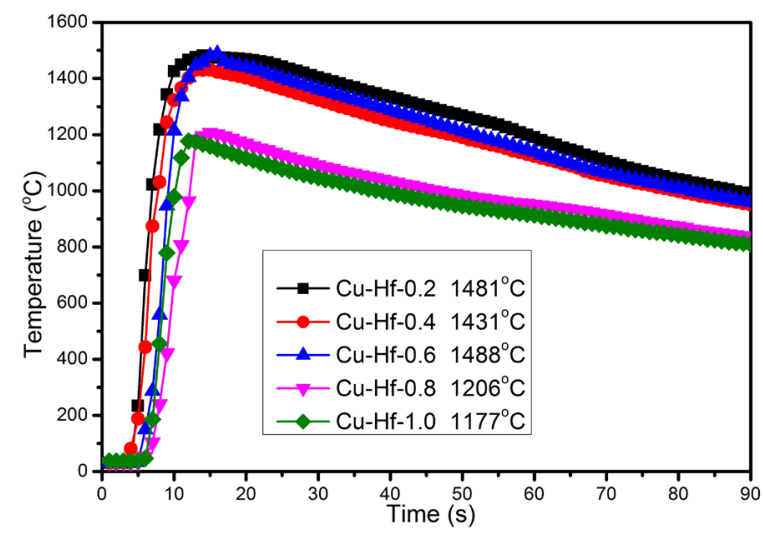

Fig. 2 Combustion temperature of the Hf-doped samples.

1431, 1488, 1206, and $1177{ }^{\circ} \mathrm{C}$. Compared with the original Zr-zirconolite $\left(1424{ }^{\circ} \mathrm{C}\right)$ [30], the temperatures of $\mathrm{Cu}-\mathrm{Hf}-0.2, \mathrm{Cu}-\mathrm{Hf}-0.4$, and $\mathrm{Cu}-\mathrm{Hf}-0.6$ are slightly higher, while those of $\mathrm{Cu}-\mathrm{Hf}-0.8$ and $\mathrm{Cu}-\mathrm{Hf}-1.0$ are much lower. Obviously, the decline of peak temperature is attributed to the elevated $\mathrm{HfO}_{2}$ content. This result reveals that the reactivity of $\mathrm{HfO}_{2}$ is lower than $\mathrm{ZrO}_{2}$. As there is heat dissipation during the combustion reaction and subsequent measurement, the real temperatures should be much higher than the measured ones. Anyhow, these temperatures are adequate for subsequent pressing as they are higher than the melting point of resultant $\mathrm{Cu}\left(1083{ }^{\circ} \mathrm{C}\right)$. Because of the existence of liquid $\mathrm{Cu}$, the as-synthesized samples can be readily densified under optimal time delay of combustion.

The phase compositions of Hf-doped samples were characterized with the XRD patterns illustrated in Fig. 3. All these samples show identical phase composition with $x$ value of $0.2-1.0$. The phase composition deviates slightly from the original design. 2M-zirconolite $\left(\mathrm{CaZr}_{1-x} \mathrm{Hf}_{x} \mathrm{Ti}_{2} \mathrm{O}_{7}\right.$, PDF No. 84-0163) and copper $(\mathrm{Cu}$, PDF No. 99-0034) are identified as the major phases. However, a small amount of perovskite $\left(\mathrm{CaTiO}_{3}, \mathrm{PDF}\right.$
No. 22-0153) is detected as the minor phase, which is also discovered in our previous study [30]. As an important constituent phase of Synroc C, the minor perovskite phase is a valuable supplement of zirconolite for nuclear waste immobilization [22]. The trace of $\mathrm{HfO}_{2}$ is not detected even in the Cu-Hf-1.0 sample, which indicates $\mathrm{HfO}_{2}$ has been successfully incorporated into the lattice crystal of ceramic phases as solid solution. The Zr-zirconolite transforms to Hf-zirconolite when the $x$ value is elevated to 1.0. According to the previous study [39], the $\mathrm{Zr}$ site of zirconolite could be totally occupied by $\mathrm{Hf}$ under solid state reaction route. This result of $\mathrm{HfO}_{2}$ incorporation is also achieved for the CS process with loading capacity as high as 34.12 $\mathrm{wt} \%$. Figure 4 exhibits the refined XRD pattern of $\mathrm{Cu}-\mathrm{Hf}-0.6$ sample. This result further testifies the phase composition as Hf-bearing zirconolite, perovskite, and $\mathrm{Cu}$ are identified as the constituent phases.

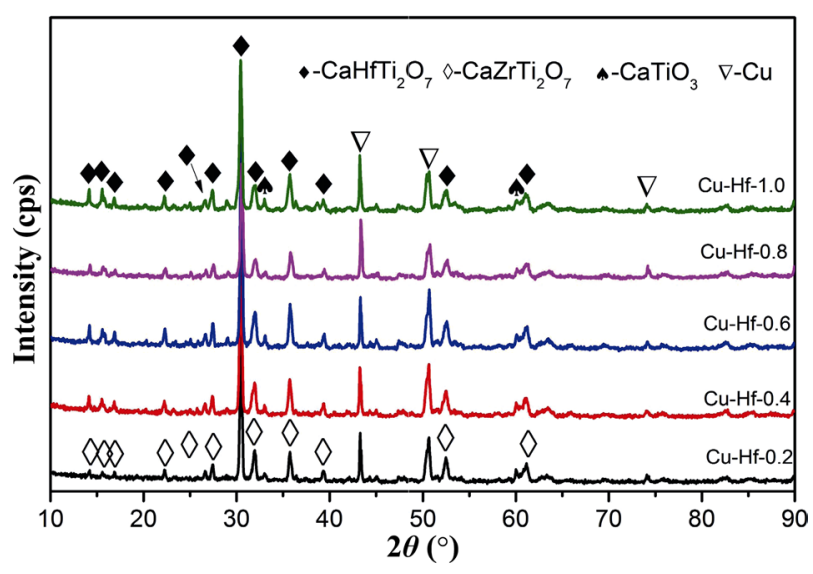

Fig. 3 XRD patterns of the Hf-doped samples with $x$ value of $0.2-1.0$.

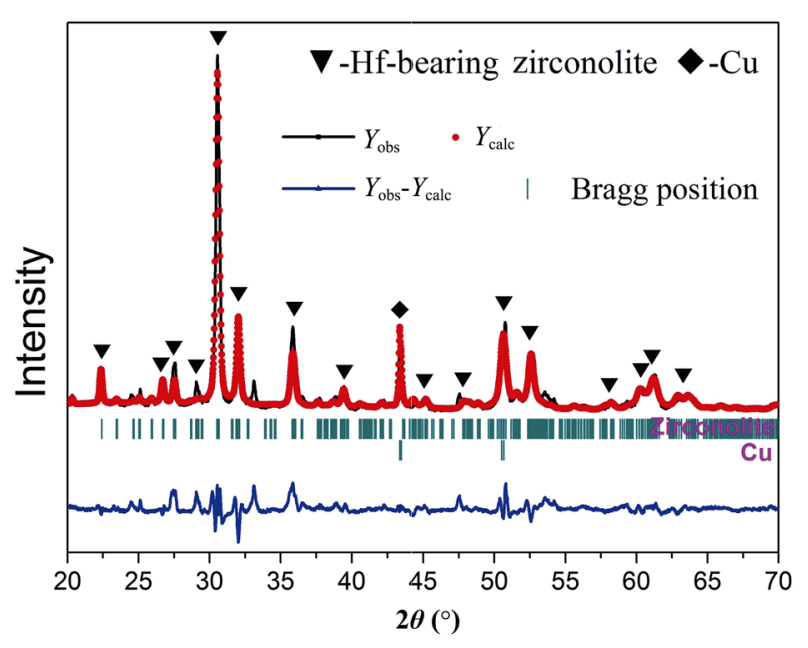

Fig. 4 Rietveld refined XRD pattern of the Cu-Hf-0.6 sample. 


\section{2 SEM-EDX analysis of the Hf-bearing samples}

The phase composition and microstructure of Hf-doped samples $(x=0.2-1.0)$ were further characterized by the SEM and EDX analysis. Typical back-scattered electron (BSE) images of all the Hf-doped ceramics are shown in Fig. 5. Few micropores can be observed in the surface images, which indicate all the Hf-doped samples were well densified. Meanwhile, three different phases with distinct contrast discrepancies can be detected in the polish surfaces. The metallic $\mathrm{Cu}$ always demonstrates circular particle morphology with different size, which is separated from the main ceramic phase with clear grain boundary as shown in Figs. 5(a)-5(e). Besides $\mathrm{Cu}$, the coexistence of two phases can be observed, which are reflected as "Z" and "P" for zirconolite and perovskite phases respectively. The Hf-zirconolite phase is observed with lighter contrast while the pervoskite phase in darker contrast. It is distinctly demonstrated that zirconolite is the matrix phase while perovskite is the dispersion phase. Figure 5(f) is the fracture surface of $\mathrm{Cu}-\mathrm{Hf}-0.6$ sample, which exhibits a dense microstructure with tightly contacted submicron sized grains. The growth step can also be observed from the grains, which reveals the feature of combustion synthesis as the reaction speed is high and soaking time is short.

EDX mapping and spotting analysis were conducted to further analyze the phase composition, elemental distribution, and Hf occupation of the $\mathrm{Cu}-\mathrm{Hf}-0.6$ sample. The elemental mapping images are presented in Fig. 6. The representative BSE image of Fig. 6(a) supports the coexistence of "A" and "B" phases. Obviously, the " $\mathrm{B}$ " area must be $\mathrm{Cu}$ phase, which is testified by the EDX mapping image of Fig. 6(e). The "A" phase should be Hf-bearing zirconolite, which demonstrates as the ceramic matrix. It is worth noting that the enrichment of $\mathrm{Cu}$ and $\mathrm{Hf}$ elements is slightly overlapped in the same area. Hf not only appears in the matrix $\mathrm{A}$ area, but also exists in the $\mathrm{Cu}$ phase. This phenomenon is strange as there is no peak corresponding to $\mathrm{Hf}$ or $\mathrm{HfO}_{2}$ in the XRD pattern. The subsequent EDX spotting analysis demonstrates that Hf has not been detected in the $\mathrm{Cu}$ phase. This phenomenon of $\mathrm{Hf}$ in $\mathrm{Cu}$ phase is related with the adjacent energy characteristic peaks of $\mathrm{Cu}$ and $\mathrm{Hf}$ in the EDX analysis (Hf: $\mathrm{K} \alpha=8.040, \mathrm{~K} \beta=8.903, \mathrm{Cu}: \mathrm{K} \alpha$ $=7.898, \mathrm{~K} \beta=9.021$ ).

EDX spotting analysis was conducted to further determine the chemical formulations of constituent phases. The EDX spotting image of "A" phase in Fig. 6(a) is presented in Figs. 7(a) and 7(b). Similar as the EDX mapping results, the existence of $\mathrm{Ca}, \mathrm{Ti}, \mathrm{Zr}, \mathrm{Hf}$, and $\mathrm{O}$ in the EDX spotting spectra indicates that the "A" phase is Hf-bearing zirconolite phase. At least five points of "A" area were calculated to obtain the average elemental quantities as listed in Fig. 7(b). The standard deviations for the average elemental quantities are included in the brackets. Based on this data, the chemical formulation of Hf-bearing zirconolite phase is calculated as $\mathrm{Ca}_{0.82} \mathrm{Zr}_{0.49} \mathrm{Hf}_{0.68} \mathrm{Ti}_{1.92} \mathrm{O}_{7}$. Compared with the designed formulation of $\mathrm{Cu}-\mathrm{Hf}-0.6$ sample $\left(\mathrm{CaZr}_{0.4} \mathrm{Hf}_{0.6} \mathrm{Ti}_{2} \mathrm{O}_{7}\right)$, the obtained zirconolite phase is slightly deficient in $\mathrm{Ca}$ and $\mathrm{Ti}$ while rich in $\mathrm{Zr}$ and $\mathrm{Hf}$. This result is reasonable as perovskite is formed as the minor phase. The perovskite phase consumes $\mathrm{Ca}$ and Ti elements, which leads to the main zirconolite phase deficient in $\mathrm{Ca}$ and rich in $\mathrm{Zr}$. However, the elemental composition is close to the original design and the promising chemical flexibility of zirconolite is verified with the maintaining of $2 \mathrm{M}$ zirconolite structure.

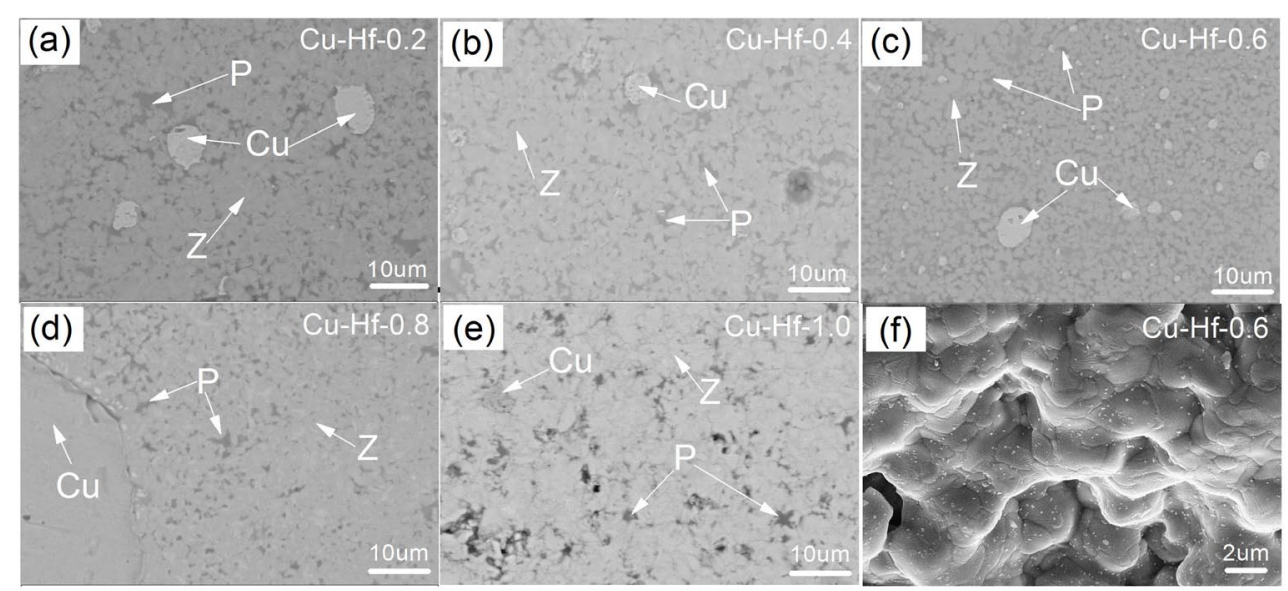

Fig. 5 BSE images of the Hf-doped samples with $x=0.2-1.0$ : (a) Cu-Hf-0.2, (b) Cu-Hf-0.4, (c) Cu-Hf-0.6, (d) Cu-Hf-0.8, (e) $\mathrm{Cu}-\mathrm{Hf}-1.0$, (f) fracture section of the Cu-Hf-0.6 sample. 


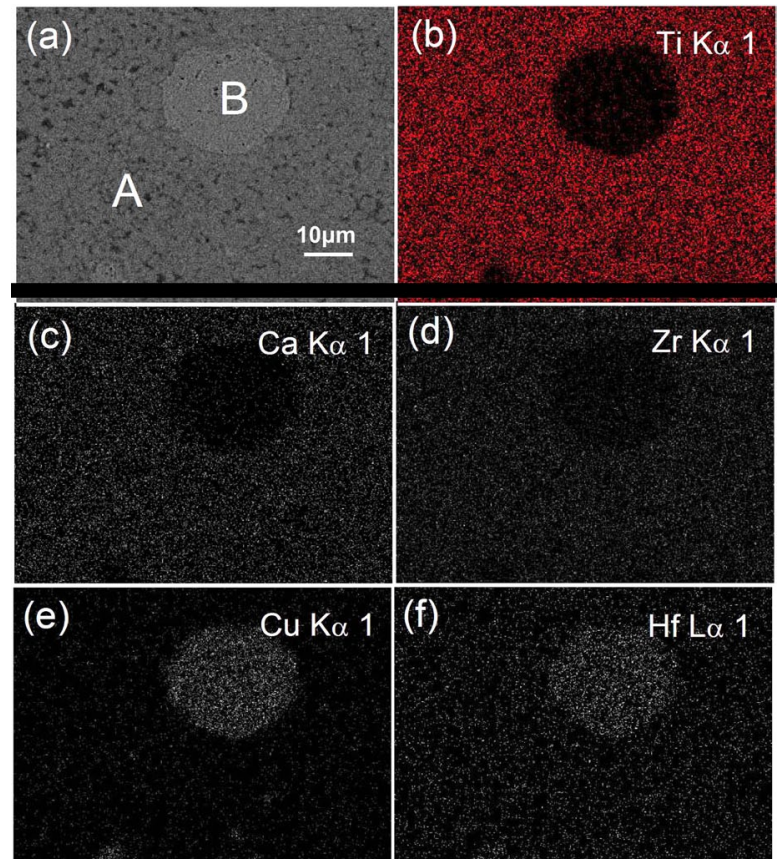

Fig. 6 SEM-EDX mapping images of the $\mathrm{Cu}-\mathrm{Hf}-0.6$ sample: (a) representative BSE image, (b)-(f) elemental distribution of $\mathrm{Ti}, \mathrm{Ca}, \mathrm{Zr}, \mathrm{Cu}$, and $\mathrm{Hf}$ elements.
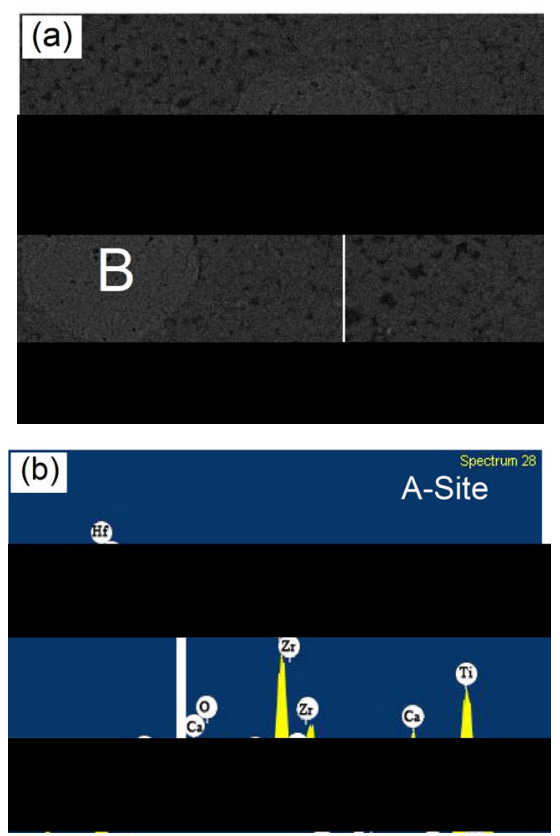

Fig. 7 EDX spotting results of $\mathrm{Cu}-\mathrm{Hf}-0.6$ sample: (a) representative BSE image, (b) elemental spotting analysis of the "A" region.

\section{3 Chemical stability of the Cu-Hf-0.6 sample}

The Cu-Hf-0.6 sample was selected for the standard MCC-1 leaching test. The 1-42-day normalized leaching rates of $\mathrm{Ca}, \mathrm{Cu}$, and $\mathrm{Hf}$ are measured and illustrated in Fig. 8. With the increase of soaking

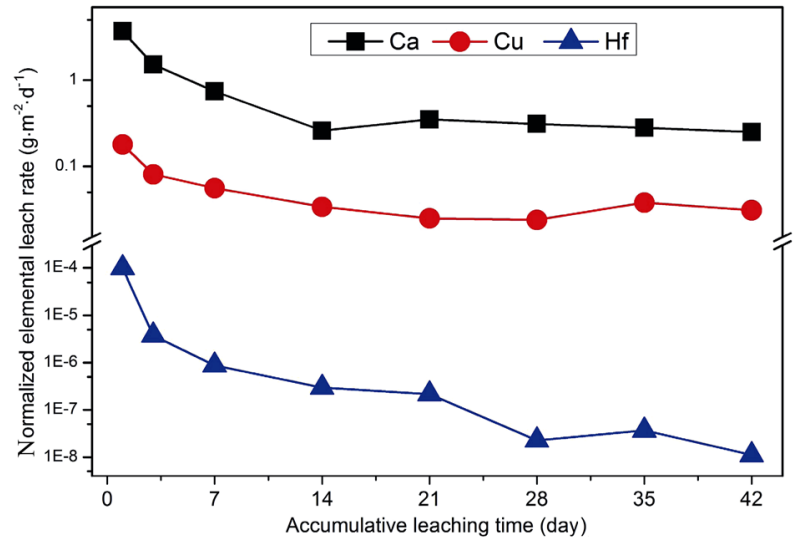

Fig. 8 1-42-day normalized leaching rates of the $\mathrm{Cu}-\mathrm{Hf}-0.6$ sample for the $\mathrm{Ca}, \mathrm{Cu}$, and $\mathrm{Hf}$ elements.

duration, all the normalized leaching rates exhibit a congruent decreasing tendency. The $L R_{\mathrm{Ca}}$ and $L R_{\mathrm{Cu}}$ values are almost unchanged after 21-day leaching. The 42-day $L R_{\mathrm{Ca}}$ and $L R_{\mathrm{Cu}}$ are computed to be 0.25 and $3.10 \times 10^{-2} \mathrm{~g} \cdot \mathrm{m}^{-2} \cdot \mathrm{d}^{-1}$. Hf is the most leaching resistant element with the 42 -day $L R_{\mathrm{Hf}}$ of $1.11 \times 10^{-8} \mathrm{~g} \cdot \mathrm{m}^{-2} \cdot \mathrm{d}^{-1}$. This value is almost the detection limit of ICP-MS. As there is metallic $\mathrm{Cu}$ remained in this waste form, the aqueous durability will be affected by this foreign phase. As the existence of $\mathrm{Cu}$ has not been considered in the $S_{\mathrm{A}}$ calculation, the leaching surface area of Hf-bearing zirconolite phase should be lower than the computed value. On other words, the actual $L R_{\mathrm{Ca}}$ and $L R_{\mathrm{Hf}}$ should be slightly higher than the calculated values in Fig. 8, while the $L R_{\mathrm{Cu}}$ value should be much lower. Anyhow, the leaching rates of $\mathrm{Ca}, \mathrm{Cu}$, and $\mathrm{Hf}$ are lower than or comparable to borosilicate glass (about $10^{-2} \mathrm{~g} \cdot \mathrm{m}^{-2} \cdot \mathrm{d}^{-1}, 90{ }^{\circ} \mathrm{C}$ ) $[40,41]$. Compared with zirconolite and pyrochlore based waste forms prepared by CS, hot pressing (HP), and hot isostatic pressing (HIP) $[22,42-45]$, the leaching rates of $\mathrm{Ca}$ and $\mathrm{Cu}$ in this research are much higher. Nevertheless, the Hf-bearing zirconolite-rich composite waste form is a durable waste form and the combustion synthesis is a rapid route for nuclear waste disposal.

\section{Conclusions}

In this study, Hf was employed as the surrogate of tetravalent actinide nuclides. Hf-doped zirconolite-rich composite waste forms were rapidly prepared using $\mathrm{CS} / \mathrm{QP}$ process. The generated temperature of CS is higher than the melting point of $\mathrm{Cu}$, which leads to liquid phase sintering to obtain highly densified 
specimen. The $\mathrm{Zr}$ site can be totally occupied by $\mathrm{Hf}$ $(x=1.0)$ and the $2 \mathrm{M}$ zirconolite structure can be maintained. A small amount of perovskite impurity phase is detected in the final products. The aqueous durability of selected sample (Cu-Hf-0.6) was evaluated, where the 42-day normalized leaching rates $\left(L R_{i}\right)$ of $\mathrm{Ca}$, $\mathrm{Cu}$, and $\mathrm{Hf}$ are measured to be $0.25,3.10 \times 10^{-2}$, and $1.11 \times 10^{-8} \mathrm{~g} \cdot \mathrm{m}^{-2} \cdot \mathrm{d}^{-1}$. These results demonstrate that the $\mathrm{CS} / \mathrm{QP}$ route is suitable for the preparation of Hf-zirconolite waste forms for the immobilization of $\mathrm{HfO}_{2}$ with loading capacity as high as $34 \mathrm{wt} \%$.

\section{Acknowledgements}

We sincerely appreciate the projects supported by the National Natural Science Foundation of China (Nos. 51202203 and 51672228), the Project of State Key Laboratory of Environment-friendly Energy Materials (Nos. 16kffk05 and 17FKSY0104, Southwest University of Science and Technology), and Science Development Foundation of China Academy of Engineering Physics.

\section{References}

[1] International Atomic Energy Agency. Design and operation of high level waste. Vitrification and storage facility. Technical Report Series No. 176. IAEA, Vienna, 1977.

[2] Ojovan MI, Lee WE. Principles of nuclear waste management. In: An Introduction to Nuclear Waste Immobilisation. Elsevier, 2005: 71-79.

[3] Weber WJ, Navrotsky A, Stefanovsky S, et al. Materials science of high-level nuclear waste immobilization. MRS Bull 2009, 34: 46-53.

[4] Ringwood AE, Kesson SE, Ware NG, et al. Immobilisation of high level nuclear reactor wastes in SYNROC. Nature 1979, 278: 219-223.

[5] Matzke HJ, Ray ILF, Seatonberry BW, et al. Incorporation of transuranic elements in titanate nuclear waste ceramics. J Am Ceram Soc 1990, 73: 370-378.

[6] Lee WE, Gilbert M, Murphy ST, et al. Opportunities for advanced ceramics and composites in the nuclear sector. $J$ Am Ceram Soc 2013, 96: 2005-2030.

[7] Vance ER, Ball CJ, Day RA, et al. Actinide and rare earth incorporation into zirconolite. J Alloys Compd 1994, 213214: 406-409.

[8] Ewing RC, Weber WJ, Lian J. Nuclear waste disposalPyrochlore $\left(\mathrm{A}_{2} \mathrm{~B}_{2} \mathrm{O}_{7}\right)$ : Nuclear waste form for the immobilization of plutonium and "minor" actinides. J Appl Phys 2004, 95: 5949-5971.

[9] Zhang KB, Wen GJ, Zhang HB, et al. Self-propagating high-temperature synthesis of $\mathrm{Y}_{2} \mathrm{Ti}_{2} \mathrm{O}_{7}$ pyrochlore and its aqueous durability. $J$ Nucl Mater 2015, 465: 1-5.
[10] Peng L, Zhang KB, He ZS, et al. Self-propagating high-temperature synthesis of $\mathrm{ZrO}_{2}$ incorporated $\mathrm{Gd}_{2} \mathrm{Ti}_{2} \mathrm{O}_{7}$ pyrochlore. J Adv Ceram 2018, 7: 41-49.

[11] Zhang KB, He ZS, Peng L, et al. Self-propagating synthesis of $\mathrm{Y}_{2-x} \mathrm{Nd}_{x} \mathrm{Ti}_{2} \mathrm{O}_{7}$ pyrochlore and its aqueous durability as nuclear waste form. Scripta Mater 2018, 146: 300-303.

[12] Zhang KB, He ZS, Xue JL, et al. Self-propagating synthesis of $\mathrm{Y}_{2-x} \mathrm{Nd}_{x} \mathrm{Ti}_{2} \mathrm{O}_{7}$ pyrochlores using $\mathrm{CuO}$ as the oxidant and its characterizations as waste form. $\mathrm{J} \mathrm{Nucl}$ Mater 2018, 507: 93-100.

[13] Strachan DM, Scheele RD, Buck EC, et al. Radiation damage effects in candidate titanates for $\mathrm{Pu}$ disposition: Zirconolite. J Nucl Mater 2008, 372: 16-31.

[14] Cheary RW. Zirconolite $\mathrm{CaZr}_{0.92} \mathrm{Ti}_{2.08} \mathrm{O}_{7}$ from 294 to 1173 K. J Solid State Chem 1992, 98: 323-329.

[15] White TJ. The microstructure and microchemistry of synthetic zirconolite, zirkelite and related phases. $\mathrm{Am}$ Mineral 1984, 69: 1156-1172.

[16] Coelho AA, Cheary RW, Smith KL. Analysis and structural determination of Nd-substituted zirconolite-4M. J Solid State Chem 1997, 129: 346-359.

[17] Lumpkin GR. Alpha-decay damage and aqueous durability of actinide host phases in natural systems. $J$ Nucl Mater 2001, 289: 136-166.

[18] Ewing RC. Nuclear waste forms for actinides. P Natl Acad Sci USA 1999, 96: 3432-3439.

[19] Vance ER. Synroc: A suitable waste form for actinides. MRS Bull 1994, 19: 28-32.

[20] Jafar M, Sengupta P, Achary SN, et al. Phase evolution and microstructural studies in $\mathrm{CaZrTi}_{2} \mathrm{O}_{7}-\mathrm{Nd}_{2} \mathrm{Ti}_{2} \mathrm{O}_{7}$ system. $J$ Am Ceram Soc 2014, 97: 609-616.

[21] Teng YC, Wang SL, Huang Y, et al. Low-temperature reactive hot-pressing of cerium-doped titanate composite ceramics and their aqueous stability. J Eur Ceram Soc 2014, 34: 985-990.

[22] Zhang Y, Stewart MWA, Li H, et al. Zirconolite-rich titanate ceramics for immobilisation of actinides-Waste form/HIP can interactions and chemical durability. $J \mathrm{Nucl}$ Mater 2009, 395: 69-74.

[23] Sun SK, Stennett MC, Corkhill CL, et al. Reactive spark plasma synthesis of $\mathrm{CaZrTi}_{2} \mathrm{O}_{7}$ zirconolite ceramics for plutonium disposition. J Nucl Mater 2018, 500: 11-14.

[24] Muthuraman M, Patil KC, Senbagaraman S, et al. Sintering, microstructural and dilatometric studies of combustion synthesized synroc phases. Mater Res Bull 1996, 31: 1375-1381.

[25] Barinova TV, Borovinskaya IP, Ratnikov VI, et al. SHS immobilization of radioactive wastes. Key Eng Mater 2001, 217: 193-200.

[26] Cao G, Orrù R. Self-propagating reactions for environmental protection: State of the art and future directions. Chem Eng J 2002, 87: 239-249.

[27] Mao XH, Qin ZG, Yuan XN, et al. Immobilization of 
simulated radioactive soil waste containing cerium by self-propagating high-temperature synthesis. J Nucl Mater 2013, 443: 428-431.

[28] Zhang KB, Yin D, Han PW, et al. Two-step synthesis of zirconolite-rich ceramic waste matrice and its physicochemical properties. Int J Appl Ceram Technol 2018, 15: 171-178.

[29] Zhang KB, Wen GJ, Zhang HB, et al. Self-propagating high-temperature synthesis of $\mathrm{CeO}_{2}$ incorporated zirconoliterich waste forms and the aqueous durability. J Eur Ceram Soc 2015, 35: 3085-3093.

[30] Zhang KB, Yin D, Peng L, et al. Self-propagating synthesis and $\mathrm{CeO}_{2}$ immobilization of zirconolite-rich composites using $\mathrm{CuO}$ as the oxidant. Ceram Int 2017, 43: 1415-1423.

[31] Szajman J, Smart RSC, Myhra S. X-ray photoelectron spectroscopy studies of valence states of cerium and uranium in SYNROC C. Surf Coat Technol 1987, 30: 333-342.

[32] Holgado JP, Alvarez R, Munuera G. Study of $\mathrm{CeO}_{2}$ XPS spectra by factor analysis: Reduction of $\mathrm{CeO}_{2}$. Appl Surf Sci 2000, 161: 301-315.

[33] Cachia JN, Deschanels X, den Auwer C, et al. Enhancing cerium and plutonium solubility by reduction in borosilicate glass. J Nucl Mater 2006, 352: 182-189.

[34] Curti E, Grolimund D, Borca CN. A micro-XAS/XRF and thermodynamic study of $\mathrm{Ce}^{\mathrm{III} / \mathrm{IV}}$ speciation after long-term aqueous alteration of simulated nuclear waste glass: Relevance for predicting Pu behavior? Appl Geochem 2012, 27: 56-63.

[35] Emsley J. The Elements. Oxford: Clarendon Press, 1992.

[36] Perera DS, Stewart MWA, Li HJ, et al. Tentative phase relationships in the system $\mathrm{CaHfTi}_{2} \mathrm{O}_{7}-\mathrm{Gd}_{2} \mathrm{Ti}_{2} \mathrm{O}_{7}$ with up to $15 \mathrm{~mol} \%$ additions of $\mathrm{Al}_{2} \mathrm{TiO}_{5}$ and $\mathrm{MgTi}_{2} \mathrm{O}_{5}$. J Am Ceram Soc 2004, 85: 2919-2924.

[37] Shannon RD. Revised effective ionic radii and systematic studies of interatomic distances in halides and chalcogenides. Acta Cryst 1976, A32: 751-767.

[38] ASTM C1220-98. Standard test method for static leaching of monolithic waste forms for disposal of radioactive waste. West Conshohocken, PA, USA, 1998.
[39] Caurant D, Loiseau P, Bardez I. Structural characterization of Nd-doped Hf-zirconolite $\mathrm{Ca}_{1-x} \mathrm{Nd}_{x} \mathrm{HfTi}_{2-x} \mathrm{Al}_{x} \mathrm{O}_{7}$ ceramics. $J$ Nucl Mater 2010, 407: 88-99.

[40] Smith KL, Lumpkin GR, Blackford MG, et al. The durability of synroc. J Nucl Mater 1992, 190: 287-294.

[41] Guittonneau C, Gin S, Godon N, et al. A 25-year laboratory experiment on French SON68 nuclear glass leached in a granitic environment-First investigations. $J$ Nucl Mater 2011, 408: 73-89.

[42] Teng YC, Wang SL, Huang Y, et al. Low-temperature reactive hot-pressing of cerium-doped titanate composite ceramics and their aqueous stability. J Eur Ceram Soc 2014, 34: 985-990.

[43] Cai X, Teng YC, Wu L, et al. The synthesis and chemical durability of Nd-doped single-phase zirconolite solid solutions. J Nucl Mater 2016, 479: 455-460.

[44] He ZS, Zhang KB, Peng L, et al. Self-propagating plus quick pressing synthesis and characterizations of $\mathrm{Gd}_{2-x} \mathrm{Nd}_{x} \mathrm{Ti}_{1.3} \mathrm{Zr}_{0.7} \mathrm{O}_{7}(0 \leqslant x \leqslant 1.4)$ pyrochlores. J Nucl Mater 2018, 504: 61-67.

[45] He ZS, Zhang KB, Xue JL, et al. Self-propagating chemical furnace synthesis of nanograin $\mathrm{Gd}_{2} \mathrm{Zr}_{2} \mathrm{O}_{7}$ ceramic and its aqueous durability. J Nucl Mater 2018, 512: 385-390.

Open Access This article is licensed under a Creative Commons Attribution 4.0 International License, which permits use, sharing, adaptation, distribution and reproduction in any medium or format, as long as you give appropriate credit to the original author(s) and the source, provide a link to the Creative Commons licence, and indicate if changes were made.

The images or other third party material in this article are included in the article's Creative Commons licence, unless indicated otherwise in a credit line to the material. If material is not included in the article's Creative Commons licence and your intended use is not permitted by statutory regulation or exceeds the permitted use, you will need to obtain permission directly from the copyright holder.

To view a copy of this licence, visit http://creativecommons.org/licenses/by/4.0/. 